\title{
Gender-related differences of renal mass supply and metabolic demand after living donor kidney transplantation
}

Oh CK, Lee BM, Jeon KO, Kim HJ, Pelletier SJ, Kim SI, Kim YS. Genderrelated differences of renal mass supply and metabolic demand after living donor kidney transplantation.

Clin Transplant 2006: 20: 163-170. (C) Blackwell Munksgaard, 2006

Abstract: Kidney donation from female donors to male recipients has been reported to be associated with decreased allograft survival. Whether there was a gender-related inadequacy between donor nephron supply and recipient functional demand was investigated in this study. One hundred ninety-five living donor kidney transplant recipients that had neither ischemic injury, episode of rejection, nor any complication were included. Weights and heights of both donors and recipients were recorded to calculate body surface area, lean body weight, and body mass index. The donated kidney was weighed just after cold flush, and the recipient's serum creatinine (Scr) was measured on a daily basis postoperatively. When the recipient's Scr reached the baseline, a 24-h urine was collected for the amount of proteinuria (Upr), creatinine excretion (Ucr) and creatinine clearance (Ccr) calculation. The effect of donor and recipient gender was analysed by independent sample $t$-test. On average, male donors and recipients were heavier and taller than females.

However, the mass of kidneys donated from men and women were not statistically different. The gender-related differences in post-transplant Scr and Ucr of recipients were associated with the differences in the parameters of metabolic demands of recipients rather than with the weight of implanted kidney (renal mass supply) or with pre-operative renal functions of donors (functional supply). The early graft function is not determined by donor gender. The effect of recipient gender on the graft function depends on the metabolic demands, which are higher in male recipients.

\author{
Chang-Kwon Oha ${ }^{\mathrm{a}}$,Byung Mo Lee ${ }^{\mathrm{a}}$,

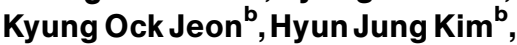 \\ Shawn J. Pelletier ${ }^{c}$, Soon II Kim ${ }^{\text {b }}$ \\ and Yu Seun Kim ${ }^{b}$ \\ aDepartment of Surgery, Ajou University \\ School of Medicine, Yeongtong-Gu, Suwon, \\ Korea, 'Department of Surgery, Yonsei \\ University College of Medicine, Seodaemun- \\ Ku, Seoul, Korea and ${ }^{\mathrm{C} D e p a r t m e n t ~ o f ~ S u r g e r y, ~}$ \\ University of Michigan, Ann Arbor, MI, USA
}

Key words: gender - graft function - kidney transplantation - nephron

Corresponding author: Chang-Kwon Oh, MD, Department of Surgery, Ajou University School of Medicine, 5 Wonchon-Dong, Yeongtong-Gu, Suwon 442-721, Korea. Tel.: 8231219 5199; fax: 8231219 5755; e-mail: ohck@ajou.ac.kr

Accepted for publication 10 October 2005
Donor and recipient gender influences many aspects of kidney transplantation. However, the precise nature of these interactions is still controversial. Inferior graft survival with females donating kidneys to male recipients has been reported $(1,2)$. In a largescale multivariate analysis, female recipients have been demonstrated to have an increased risk of acute rejection and a decreased risk for the development of chronic allograft failure (3). In contrast, a single center multivariate analysis of graft survival showed that donor and recipient gender was not significant (4).
Potential explanations of the gender effect on renal allotransplantation may include immunologic or non-immunologic mechanisms. An intriguing hypothesis has been suggested that female kidneys contain fewer nephrons (nephron underdosing) (5). An insufficient number of functioning nephrons might fail to meet the metabolic demands of the kidney recipient. As the hyperfiltration hypothesis was suggested to be an important factor in the progression of kidney disease (6), evidence has been accumulated implicating hyperfiltration as a risk 


\section{Oh et al.}

factor for the development of chronic allograft failure (7). Diminished long-term survival of kidneys donated from women as compared with men may be explained by an inadequacy between the donor's nephron supply and the recipient's functional demand (8). Other mechanisms that may contribute to the gender effect of donors include that female kidneys are more antigenic and more susceptible to rejection (9), or that a smaller female kidney might be more susceptible to ischemic injury, immunologic reaction or nephrotoxicity (10). Other potential explanations include the direct influence of sex hormones on renal hemodynamics, mesangial cell proliferation and extracellular matrix metabolism. Also, sex hormones influence the synthesis and release of vasoactive substances, cytokines and other growth factors, which in turn are capable of altering the progression of renal disease (11). In addition, various humoral and cellular immune responses are regulated by sex hormones (12) that can enhance or reverse the immunosuppressive activity of cyclosporine $(13,14)$.

Theoretically, gender may impact early graft function following kidney transplantation by associated differences in donor nephron mass supply and recipient functional demand. To address these questions, we compared the differences in the graft weight of donated kidney prior to implantation between male and female donors as well as in the metabolic demands of recipients. Furthermore, we examined the differences in the early graft function based on donor gender, graft mass and recipient metabolic demand.

\section{Patients and methods}

\section{Study population}

A prospective analysis of the effect of renal allograft mass on outcome after living donor kidney transplantation was performed at Ajou University and Yonsei University between 1999 and 2003. We attempted to specifically analyse the impact of the gender-related differences in metabolic demands and renal supply on graft outcome. In order to limit other factors that might affect renal allograft function, the study population was restricted to living donor transplants demonstrating immediate function. To eliminate the possible impact of immunologic or non-immunologic factors on graft function, we excluded recipients with pre- or posttransplant diabetes, kidney transplants from cadaveric donors, post-transplant ischemic injuries of the graft, episodes of rejection, drug toxicities, systemic or local infections or any complications such as vascular or urologic adverse events post-operatively that result in functional decrease of the kidney graft. We considered the donor with proteinuria (Upr) more than $1000 \mathrm{mg} / \mathrm{d}$, with body surface area (BSA) adjusted creatinine clearance (Ccr) less than $50 \mathrm{~mL} /$ $\min 1.73 \mathrm{~m}^{2}$, or with blood pressure higher than $150 \mathrm{mmHg}$ systole or $100 \mathrm{mmHg}$ diastole even with one antihypertensive medication, as unsuitable. Immunosuppression consisted of cyclosporine $(\mathrm{n}=149,76.4 \%)$ or tacrolimus $(\mathrm{n}=46,23.6 \%)$, corticosteroids and either azathioprine or mycophenolate mofetil. Cyclosporine or tacrolimus was given orally at a dose of 10 or $0.2 \mathrm{mg} / \mathrm{kg} / \mathrm{d}$, respectively, starting at two d prior to transplantation. Within a month after transplantation, the dose of the drug was individually adjusted with goal trough blood level between 200 and $250 \mathrm{ng} / \mathrm{mL}$ for cyclosporine or between 10 and $15 \mathrm{ng} / \mathrm{mL}$ for tacrolimus.

\section{Variables investigated}

The donated kidney was weighed just after cold flush during the operative procedures. The recipient's serum creatinine (Scr) was measured on a daily basis post-operatively. When the Scr of the recipient reached the baseline level within a month posttransplantation, the recipient's 24 -h urine was collected for the amount of Upr, creatinine excretion (Ucr) and Ccr calculation. We defined the baseline level of creatinine as the recipient's Scr reached the nadir and increased less than $20 \%$ of the nadir in three consecutive days. When the recipient's Scr increased more than $20 \%$ of the nadir within three consecutive days, the cases were excluded from this study population and evaluated to determine the cause of such renal dysfunction with ultrasonography and Doppler, radioisotope scan, renal graft biopsy, etc. The causes of renal dysfunction in the excluded cases consisted of ischemic injuries of the graft, episodes of rejection, drug toxicities, systemic or local infections or other complications such as vascular or urologic adverse events. We measured the systolic and diastolic blood pressure of recipients four times every day post-transplantation, and controlled blood pressures with a goal of under $150 \mathrm{mmHg}$ systole and $90 \mathrm{mmHg}$ diastole with antihypertensive medications. The cases of uncontrolled hypertension in any five consecutive post-transplant days even with calcium channel blockers and/or $\alpha$-/ $\beta$-adrenergic blockers were excluded with accordance to the prospective exclusion criteria. None of this study population had taken ACE inhibitors or angiotensin II blockers.

The recipients were also weighed on a daily basis post-transplantation. Dry weight of recipients was used as a parameter of metabolic demands. Dry weight was defined as the recipient's body weight 
within a month post-transplantation when the Scr reached baseline, the body weight of recipient maintained stable at the nadir and the recipient was not on diuretics. Heights of both donors and recipients were recorded. The BSA of both were calculated with the DuBois formula (15), the lean body weight $(\mathrm{LBW})$ with the formula, $1.10 \times$ weight $(\mathrm{kg})-128 \times$ (weight $\left.{ }^{2} /(100 \times \text { height }(\mathrm{m}))^{2}\right)$ in men or $1.07 \times$ weight $(\mathrm{kg})-148 \times\left(\right.$ weight $\left.^{2} /(100 \times \text { height }(\mathrm{m}))^{2}\right)$ in women, and the body mass index (BMI) with the formula, weight $(\mathrm{kg}) /$ height $(\mathrm{m})^{2}$. Other donor and recipient characteristics were recorded including age, gender, duration of dialysis, degree of HLA match and type or dose of immunosuppression.

There are many measures of renal function such as excretion, filtration, reabsortion, erythropoetin synthesis, electrolyte or acid base balance, calcium metabolism, etc. In this study, we analyzed the Scr, the amount of Ucr, the amount of Upr and the Ccr as the parameters of renal function. We defined the renal function as the parameters analysed in this study such as Scr, the amount of Ucr, the amount of Upr and Ccr.

\section{Statistical analysis}

The variables were analysed with accordance to donor and recipient gender by independent sample $t$-test and $\chi^{2}$ statistics using SPSS (release 10.0, Chicago, IL, USA), and $\mathrm{p}<0.05$ was considered significant. Continuous variables are expressed as the mean \pm standard deviation (SD).

\section{Results}

During the study period from October 1999 to March 2003, 397 kidney transplants were performed at Ajou University and Yonsei University. Two hundred and two cases were excluded. Twentynine cases from cadaveric donors, 43 cases of recipient pre- or post-transplant diabetes, 47 cases of uncontrolled hypertension in any five consecutive post-transplant days, 34 cases of rejection either biopsy-proven or clinically based, 16 cases of surgical or urologic complications, 16 cases of systemic or local infections, 39 cases of unexplained rise of Scr more than $20 \%$ of the nadir in three consecutive days were excluded. Twenty-two cases were excluded by two or more reasons. One hundred and ninety-five kidney transplant cases met the study criteria and were included in this study population. To specifically analyse the impact of the gender-related differences in metabolic demands and renal mass supply on graft function, the study population was strictly restricted to live donor transplants demonstrating immediate graft function after reperfusion.
Scr of recipient rapidly fell down and reached the nadir within a few days after transplantation. When the recipient's Scr was stable within $20 \%$ of the nadir in three consecutive days, the recipient's 24-h urine was collected. The recipient studies were done on average $7.2 \mathrm{~d}$ post-transplantation (5-14 d).

\section{Demographic characteristics and renal function by donor} gender

The demographic characteristics and renal functions of 99 male and 96 female donors were compared, as displayed in Table 1 . Male donors were significantly heavier $(\mathrm{p}<0.001)$ and taller $(\mathrm{p}<0.001)$ than female donors. Accordingly, the BSA $(\mathrm{p}<0.001)$, LBW $(\mathrm{p}<$ $0.001)$ and BMI $(p=0.021)$ of male donors were greater than those of female donors. Prior to the kidney donation, the Scr $(p<0.001)$, Ucr $(p<0.001)$ and Ccr $(p=0.041)$ of male donors were significantly greater than those of female donors. However, donor Upr was not significantly different between men and women $(p=0.091)$. Of note, donated kidneys from men and women were found to have a similar weight $(218.4 \pm 42.7$ vs. $212.5 \pm 38.1 \mathrm{~g}$, respectively; $\mathrm{p}=$ $0.310)$. The parameters of recipient's metabolic demands such as weight, height, BSA, LBW and BMI as well as post-transplant recipient's graft functions such as Scr, Ccr, Ucr and Upr were not significantly different based on donor gender $(\mathrm{p}>0.050)$.

Demographic characteristics and renal function by recipient gender

The demographic characteristics and renal function of 132 male and 63 female recipients were com-

Table 1. Demographic characteristics and renal function by donor gendera

\begin{tabular}{lccr}
\hline Donor gender & Male $(\mathrm{n}=99)$ & Female $(\mathrm{n}=96)$ & \multicolumn{1}{c}{$p$} \\
\hline Donor variables & & & \\
Age $(\mathrm{yr})$ & $37.1 \pm 11.0$ & $40.4 \pm 9.3$ & 0.125 \\
Weight $(\mathrm{kg})$ & $68.9 \pm 9.4$ & $56.9 \pm 7.6$ & $<0.001$ \\
Height $(\mathrm{cm})$ & $171.3 \pm 5.3$ & $158.9 \pm 5.4$ & $<0.001$ \\
Body surface area $\left(\mathrm{m}^{2}\right)$ & $1.80 \pm 0.13$ & $1.57 \pm 0.1$ & $<0.001$ \\
Lean body weight $(\mathrm{kg})$ & $54.8 \pm 5.3$ & $41.6 \pm 3.6$ & $<0.001$ \\
Body mass index $\left(\mathrm{kg} / \mathrm{m}^{2}\right)$ & $23.5 \pm 2.7$ & $22.5 \pm 2.8$ & 0.021 \\
& & & \\
Twenty-four hours, pre-operative & & & \\
Creatinine excretion $(\mathrm{mg} / \mathrm{d})$ & $1490.0 \pm 401.5$ & $916.2 \pm 248.9$ & $<0.001$ \\
Protein excretion $(\mathrm{mg} / \mathrm{d})$ & $67.7 \pm 71.2$ & $93.8 \pm 104.1$ & 0.091 \\
(min-max) & $(0-496.8)$ & $(2.8-645.2)$ & \\
Ccr (mL/min per 1.73 m $\left.{ }^{2}\right)$ & $97.7 \pm 24.6$ & $90.7 \pm 22.5$ & 0.041 \\
(min-max) & $(57.2-180.6)$ & $(55.3-179.4)$ & \\
Serum creatinine $(\mathrm{mg} / \mathrm{dL})$ & $1.02 \pm 0.13$ & $0.78 \pm 0.15$ & $<0.001$ \\
Kidney graft weight $(\mathrm{g})$ & $218.4 \pm 42.7$ & $212.5 \pm 38.1$ & 0.310 \\
& & &
\end{tabular}

${ }^{a}$ Continuous variables are expressed as the mean \pm standard deviation (SD).

Ccr, creatinine clearance; min, minimum; max, maximum. 


\section{Oh et al.}

Table 2. Demographic characteristics and renal function by recipient gender $^{a}$

\begin{tabular}{|c|c|c|c|}
\hline Recipient gender & $\begin{array}{l}\text { Male } \\
(n=132)\end{array}$ & $\begin{array}{l}\text { Female } \\
(n=63)\end{array}$ & $\mathrm{p}$ \\
\hline \multicolumn{4}{|l|}{ Recipient variables } \\
\hline Age (yr) & $36.2 \pm 10.5$ & $39.0 \pm 9.5$ & 0.184 \\
\hline Weight (kg) & $60.3 \pm 9.0$ & $50.1 \pm 7.6$ & $<0.001$ \\
\hline Height (cm) & $170.8 \pm 7.1$ & $158.5 \pm 5.3$ & $<0.001$ \\
\hline Body surface area $\left(m^{2}\right)$ & $1.70 \pm 0.15$ & $1.49 \pm 0.11$ & $<0.001$ \\
\hline Lean body weight (kg) & $50.2 \pm 6.0$ & $38.6 \pm 3.9$ & $<0.001$ \\
\hline Body mass index $\left(\mathrm{kg} / \mathrm{m}^{2}\right)$ & $20.6 \pm 2.6$ & $20.0 \pm 3.0$ & 0.155 \\
\hline \multicolumn{4}{|c|}{ Twenty-four hours urine, post-operative } \\
\hline $\begin{array}{l}\text { Creatinine excretion } \\
(\mathrm{mg} / \mathrm{d})\end{array}$ & $1225.2 \pm 310.3$ & $850.9 \pm 192.3$ & $3<0.001$ \\
\hline $\begin{array}{l}\text { Protein excretion }(\mathrm{mg} / \mathrm{d}) \\
\text { (min-max) }\end{array}$ & $\begin{array}{r}29.8 \pm 97.6 \\
(0-636.0)\end{array}$ & $\begin{array}{l}48.1 \pm 261.6 \\
(0-2026.0)\end{array}$ & 0.482 \\
\hline $\begin{array}{l}\operatorname{Ccr}\left(\mathrm{mL} / \mathrm{min} / 1.73 \mathrm{~m}^{2}\right) \\
(\min -\max )\end{array}$ & $\begin{array}{r}62.5 \pm 15.0 \\
(31.7-115.7)\end{array}$ & $\begin{array}{c}64.7 \pm 13.4 \\
(33.5-92.2)\end{array}$ & 0.316 \\
\hline Serum creatinine (mg/dL) & $1.43 \pm 0.33$ & $1.06 \pm 0.20$ & $<0.001$ \\
\hline Kidney graft weight (g) & $216.2 \pm 41.4$ & $214.1 \pm 38.8$ & 0.746 \\
\hline $\begin{array}{l}\text { Kidney weight/body } \\
\text { weight }(\mathrm{g} / \mathrm{kg})\end{array}$ & $3.69 \pm 1.06$ & $4.37 \pm 1.01$ & 0.532 \\
\hline
\end{tabular}

${ }^{a}$ Continuous variables are expressed as the mean \pm standard deviation (SD).

Ccr, creatinine clearance; min, minimum; max, maximum.

pared, as displayed in Table 2. Male recipients were significantly heavier $(\mathrm{p}<0.001)$ and taller $(\mathrm{p}<$ $0.001)$ than female recipients. Accordingly, the BSA $(p<0.001)$ and LBW $(p<0.001)$ of male recipients were greater than those of female recipients. After kidney transplantation, the Ucr and Scr of male recipients were significantly greater than those of female recipients $(\mathrm{p}<0.001)$. However, the Upr $(\mathrm{p}=0.482)$ and calculated $\operatorname{Ccr}(\mathrm{p}=0.316)$ of recipients were not found to be significantly different between the groups. Both male and female recipients were transplanted with kidneys with similar average weight $(216.2 \pm 41.4$ vs. $214.1 \pm 38.8 \mathrm{~g}$, respectively; $\mathrm{p}=0.746)$. Also, the pre-operative donor's kidney function (Scr, Ccr, Ucr and Upr) and metabolic demands (weight, height, BSA, LBW and BMI) were not significantly different by the recipient gender $(p>0.050)$.

\section{Demographic characteristics and renal function by gender combination of donor and recipient}

Four groups were analysed according to recipient and donor gender: male donor to male recipient $(\mathrm{MM}, \mathrm{n}=65)$, male donor to female recipient $(\mathrm{MF}$, $\mathrm{n}=34$ ), female donor to male recipient (FM, $\mathrm{n}=67)$ and female donor to female recipient (FF, $\mathrm{n}=29$ ). Demographic characteristics and renal function of the four groups were displayed in Table 3, and compared (MM vs. FM, MF vs. FF, MM vs. MF, FM vs. FF, MM vs. FF, MF vs.
FM) by independent sample $t$-test as displayed in Table 4. On the donor side, statistical differences ( $p$ $<0.050$ ) in the renal functions such as Scr and Ucr before kidney donation were found only in the pair of groups with different donor genders (MM vs. FM, MF vs. FF, MM vs. FF, MF vs. FM), in which the parameters of metabolic demands of donors such as weight, height, BSA and LBW were statistically different. The weight of donated kidney was not found different in any pair of the groups. On the recipient side, statistical differences $(\mathrm{p}<0.050)$ in the graft functions such as Scr and Ucr after kidney tansplantation were found only in the pair of groups with different recipient genders (MM vs. MF, FM vs. FF, MM vs. FF, MF vs. FM), in which the parameters of metabolic demands of recipients such as weight, height, BSA and LBW were statistically different. The weight of transplanted kidney was not found different in any pair of the groups.

No difference between groups was found on analysis of duration or type of dialysis, degree of HLA match, cold and warm ischemic times and type or dose of immunosuppression (cyclosporine or tacrolimus, dual or triple therapy).

\section{Discussion}

The influence of transplanted renal mass and the metabolic demands of kidney transplant recipients on outcome has been described using various surrogate markers. These surrogates of the balance between 'supply' and 'demand' have included recipient weight and kidney size (16), recipient BMI and kidney size (17), recipient weight and kidney weight $(8,18,19)$, recipient BSA and kidney weight (20) and recipient BMI and kidney weight (21-23) as well as recipient and donor characteristics $(24,25)$. However, among the parameters which attempt to measure the metabolic demands and nephron supply, none has been determined yet as the best proxy to predict the early graft function after kidney transplantation. In the present study, we analysed the variables of age, weight, height, BSA, LBW and BMI to attempt to control for metabolic demand. In an attempt to estimate nephron mass, graft size or graft weight might be used. Kidney size is known to be related to total body mass and increases with age and growth in children $(26,27)$. Consequently, healthy men have larger kidneys than healthy women $(28,29)$. A prior study demonstrated no significant difference between the renal volume per kilogram of body weight between men and women or between renal volume per square meter in men and women (30). In addition, a previous study has demonstrated a poor correlation between the kidney size and measured kidney 
Gender-related renal supply and metabolic demand

Table 3. Demographic characteristics and renal function by the gender combination of donors and recipients ${ }^{\mathrm{a}}$

\begin{tabular}{|c|c|c|c|c|}
\hline Gender combination & $\mathrm{MM}(\mathrm{n}=65)$ & $M F(n=34)$ & $\mathrm{FM}(\mathrm{n}=67)$ & $\mathrm{FF}(\mathrm{n}=29)$ \\
\hline \multicolumn{5}{|l|}{ Donor variables } \\
\hline Age (yr) & $36.9 \pm 10.7$ & $37.5 \pm 11.8$ & $40.0 \pm 8.8$ & $41.2 \pm 10.7$ \\
\hline Weight (kg) & $69.4 \pm 9.8$ & $68.0 \pm 8.5$ & $57.3 \pm 8.2$ & $55.9 \pm 6.0$ \\
\hline Height $(\mathrm{cm})$ & $171.7 \pm 4.8$ & $170.4 \pm 6.0$ & $159.0 \pm 5.1$ & $158.4 \pm 6.1$ \\
\hline Body surface area $\left(m^{2}\right)$ & $1.81 \pm 0.13$ & $1.79 \pm 0.13$ & $1.58 \pm 0.12$ & $1.56 \pm 0.09$ \\
\hline Lean body weight $(\mathrm{kg})$ & $55.1 \pm 5.4$ & $54.2 \pm 5.2$ & $41.8 \pm 3.8$ & $48.3 \pm 8.0$ \\
\hline Body mass index $\left(\mathrm{kg} / \mathrm{m}^{2}\right)$ & $23.5 \pm 2.9$ & $23.4 \pm 2.2$ & $22.6 \pm 2.9$ & $22.3 \pm 2.4$ \\
\hline \multicolumn{5}{|c|}{ Twenty-four hours urine, pre-operative } \\
\hline Creatinine excretion (mg/d) & $1492.4 \pm 424.3$ & $1485.5 \pm 359.8$ & $934.2 \pm 251.6$ & $874.4 \pm 241.4$ \\
\hline $\begin{array}{l}\text { Protein excretion (mg/d) } \\
\text { (min-max) }\end{array}$ & $\begin{array}{r}64.6 \pm 72.4 \\
(2.4-496.8)\end{array}$ & $\begin{array}{l}73.6 \pm 69.4 \\
(0-354.0)\end{array}$ & $\begin{array}{c}99.9 \pm 114.7 \\
(2.8-645.2)\end{array}$ & $\begin{array}{l}79.8 \pm 74.0 \\
(13.9-429.0)\end{array}$ \\
\hline $\mathrm{Ccr}\left(\mathrm{mL} / \mathrm{min} / 1.73 \mathrm{~m}^{2}\right)$ & $97.8 \pm 26.4$ & $97.5 \pm 21.2$ & $92.8 \pm 22.6$ & $85.9 \pm 21.8$ \\
\hline$(\min -\max )$ & $(57.2-180.6)$ & $(57.6-145.6)$ & $(55.3-179.4)$ & $(58.9-149.1)$ \\
\hline Serum creatinine (mg/dL) & $1.02 \pm 0.15$ & $1.02 \pm 0.11$ & $0.78 \pm 0.13$ & $0.80 \pm 0.18$ \\
\hline Kidney graft weight $(\mathrm{g})$ & $219.3 \pm 40.9$ & $216.6 \pm 46.6$ & $213.1 \pm 42.1$ & $211.2 \pm 27.6$ \\
\hline \multicolumn{5}{|l|}{ Recipient variables } \\
\hline Age (yr) & $38.4 \pm 10.9$ & $39.2 \pm 8.9$ & $34.3 \pm 9.6$ & $38.8 \pm 10.3$ \\
\hline Weight (kg) & $61.1 \pm 4.9$ & $51.4 \pm 7.6$ & $59.5 \pm 10.0$ & $48.6 \pm 77.4$ \\
\hline Height $(\mathrm{cm})$ & $171.1 \pm 5.2$ & $158.1 \pm 5.1$ & $170.4 \pm 8.7$ & $159.0 \pm 8.8$ \\
\hline Body surface area $\left(\mathrm{m}^{2}\right)$ & $1.71 \pm 0.11$ & $1.50 \pm 0.10$ & $1.69 \pm 0.17$ & $1.48 \pm 0.12$ \\
\hline Lean body weight $(\mathrm{kg})$ & $50.7 \pm 4.9$ & $39.0 \pm 3.7$ & $49.6 \pm 6.9$ & $38.1 \pm 4.2$ \\
\hline Body mass index $\left(\mathrm{kg} / \mathrm{m}^{2}\right)$ & $20.9 \pm 2.5$ & $20.6 \pm 3.2$ & $20.4 \pm 2.7$ & $19.3 \pm 2.6$ \\
\hline \multicolumn{5}{|c|}{ Twenty-four hours urine, post-operative } \\
\hline Creatinine excretion (mg/d) & $1204.1 \pm 286.5$ & $867.1 \pm 211.5$ & $1246.3 \pm 333.4$ & $831.8 \pm 168.6$ \\
\hline $\begin{array}{l}\text { Protein excretion (mg/d) } \\
\text { (min-max) }\end{array}$ & $\begin{array}{l}23.4 \pm 61.6 \\
(0-259.0)\end{array}$ & $\begin{array}{r}81.9 \pm 354.4 \\
(0-2026.0)\end{array}$ & $\begin{array}{l}36.1 \pm 123.8 \\
(0-636.0)\end{array}$ & $\begin{aligned} 9.7 & \pm 51.6 \\
(0-278.2) & \end{aligned}$ \\
\hline $\mathrm{Ccr}\left(\mathrm{mL} / \mathrm{min} / 1.73 \mathrm{~m}^{2}\right)$ & $63.3 \pm 14.5$ & $64.7 \pm 14.0$ & $61.7 \pm 15.4$ & $64.8 \pm 13.0$ \\
\hline$(\min -\max )$ & $(31.7-97.2)$ & $(33.5-92.2)$ & $(34.6-115.7)$ & $(39.6-90.6)$ \\
\hline Serum creatinine (mg/dL) & $1.37 \pm 0.30$ & $1.07 \pm 0.22$ & $1.48 \pm 0.34$ & $1.06 \pm 0.18$ \\
\hline Graft weight/weight (g/kg) & $3.66 \pm 0.90$ & $4.30 \pm 1.07$ & $3.72 \pm 1.20$ & $4.45 \pm 1.95$ \\
\hline
\end{tabular}

aContinuous variables are expressed as the mean \pm standard deviation (SD).

MM, male to male; MF, male to female; FM, female to male; FF, female to female; Ccr, creatinine clearance; min, minimum; max, maximum.

weight (31). The present study, therefore, used kidney weight to control for nephron mass. In order to determine the actual number of nephrons in the donated kidney, a routine graft biopsy would need to be performed during the operative procedures. In the present study, graft weight was used rather than nephron number on biopsy because of the associated risks of biopsy including bleeding, hematuria and arteriovenous fistula in the grafted kidney. The pre-implantation graft biopsies are relatively safer than the post-transplant biopsies using a biopsy gun or needle even ultrasonography-guided because pre-implantation biopsies could be performed under direct visualization after cold flush with preservation solution in the cold bath of back table. The site of graft biopsy can be repaired by a few stitches or bleeding from the site can be controlled by the electrocoagulator or argon beam coagulator in the operative fields. We have done the pre-implantation biopsies in the cases of cadaveric donor transplants, and transplants from donors with microscopic hematuria or mild Upr. However, in this study population, by the selection criteria, the pre-implantation biopsies were not routinely performed on a basis of risks and benefits. There are few data examining differences in renal structure between the sexes. According to a recent report (32), there is no difference in glomerular number between men and women. Although men had larger glomeruli than women, sex is not an independent determinant of glomerular volume. The occurrence of larger glomeruli in men is solely dependent on their greater body surface area.

The kidneys are heavier in men than in women according to the studies based on forensic autopsies (33) or of traumatic deaths (34). Theoretically, the weight of postmortem kidneys could differ from that of healthy living donor kidneys on the following basis. The delay between death and autopsy can alter organ weights. The cause of death can have a major influence on the organ weight, for example, the weight of an organ tends to decrease in any condition producing hypovolemic shock (35). The kidney weight can be influenced by an underlying disease prior to death, for example, diabetics have larger kidneys (36). In our study, the healthy donors were selected after the pre-operative evaluation, and the living donor kidneys were directly weighed just 


\section{Oh et al.}

Table 4. $p$ values by the independent sample $t$-test between the groups of different gender combinations of donors and recipients

\begin{tabular}{|c|c|c|c|c|c|c|}
\hline \multirow{2}{*}{$\begin{array}{l}\text { Group compared } \\
\text { Gender combinations }\end{array}$} & \multicolumn{2}{|c|}{ By donor gender } & \multicolumn{2}{|c|}{ By recipient gender } & \multirow{2}{*}{$\begin{array}{l}\text { Matched } \\
\text { MM-FF }\end{array}$} & \multirow{2}{*}{$\begin{array}{l}\text { Mismatched } \\
\text { MF-FM }\end{array}$} \\
\hline & MM-FM & MF-FF & MM-MF & FM-FF & & \\
\hline \multicolumn{7}{|l|}{ Donor variables } \\
\hline Age (yr) & 0.064 & 0.201 & 0.800 & 0.589 & 0.075 & 0.219 \\
\hline Weight (kg) & $<0.001$ & $<0.001$ & 0.475 & 0.386 & $<0.001$ & $<0.001$ \\
\hline Height (cm) & $<0.001$ & $<0.001$ & 0.225 & 0.622 & $<0.001$ & $<0.001$ \\
\hline Body surface area $\left(\mathrm{m}^{2}\right)$ & $<0.001$ & $<0.001$ & 0.365 & 0.406 & $<0.001$ & $<0.001$ \\
\hline Lean body weight $(\mathrm{kg})$ & $<0.001$ & $<0.001$ & 0.432 & 0.442 & $<0.001$ & $<0.001$ \\
\hline Body mass index $\left(\mathrm{kg} / \mathrm{m}^{2}\right)$ & 0.099 & 0.070 & 0.831 & 0.560 & 0.056 & 0.207 \\
\hline \multicolumn{7}{|c|}{ Twenty-four hours urine, pre-operative } \\
\hline Creatinine excretion (mg/d) & $<0.001$ & $<0.001$ & 0.936 & 0.282 & $<0.001$ & $<0.001$ \\
\hline Protein excretion (mg/d) & 0.037 & 0.733 & 0.554 & 0.388 & 0.353 & 0.223 \\
\hline $\operatorname{Ccr}\left(\mathrm{mL} / \mathrm{min} / 1.73 \mathrm{~m}^{2}\right)$ & 0.245 & 0.038 & 0.954 & 0.172 & 0.038 & 0.318 \\
\hline Serum creatinine (mg/dL) & $<0.001$ & $<0.001$ & 0.895 & 0.472 & $<0.001$ & $<0.001$ \\
\hline Kidney graft weight $(\mathrm{g})$ & 0.387 & 0.583 & 0.767 & 0.872 & 0.331 & 0.698 \\
\hline \multicolumn{7}{|l|}{ Recipient variables } \\
\hline Age (yr) & 0.022 & 0.875 & 0.723 & 0.040 & 0.871 & 0.014 \\
\hline Weight (kg) & 0.294 & 0.143 & $<0.001$ & $<0.001$ & $<0.001$ & $<0.001$ \\
\hline Height $(\mathrm{cm})$ & 0.570 & 0.508 & $<0.001$ & $<0.001$ & $<0.001$ & $<0.001$ \\
\hline Body surface area $\left(\mathrm{m}^{2}\right)$ & 0.315 & 0.368 & $<0.001$ & $<0.001$ & $<0.001$ & $<0.001$ \\
\hline Lean body weight $(\mathrm{kg})$ & 0.306 & 0.359 & $<0.001$ & $<0.001$ & $<0.001$ & $<0.001$ \\
\hline Body mass index $\left(\mathrm{kg} / \mathrm{m}^{2}\right)$ & 0.268 & 0.080 & 0.674 & 0.073 & 0.006 & 0.674 \\
\hline \multicolumn{7}{|c|}{ Twenty-four hours urine, post-operative } \\
\hline Creatinine excretion $(\mathrm{mg} / \mathrm{d})$ & 0.440 & 0.479 & $<0.001$ & $<0.001$ & $<0.001$ & $<0.001$ \\
\hline Protein excretion (mg/d) & 0.461 & 0.282 & 0.198 & 0.273 & 0.298 & 0.351 \\
\hline $\operatorname{Ccr}\left(\mathrm{mL} / \mathrm{min} / 1.73 \mathrm{~m}^{2}\right)$ & 0.531 & 0.970 & 0.660 & 0.343 & 0.638 & 0.350 \\
\hline Serum creatinine (mg/dL) & 0.054 & 0.854 & $<0.001$ & $<0.001$ & $<0.001$ & $<0.001$ \\
\hline Graft weight/weight (g/kg) & 0.561 & 0.334 & 0.159 & 0.783 & 0.841 & 0.562 \\
\hline
\end{tabular}

MM, male to male; MF, male to female; FM, female to male; FF, female to female; Ccr, creatinine clearance; min, minimum; max, maximum.

after removal from the healthy donors. Data on the difference of the actual weight of living donor kidneys from the confirmed healthy donors have not been reported yet. Our data showed that male donor kidneys $(218.4 \pm 42.7 \mathrm{~g})$ were not statistically different $(\mathrm{p}=0.310)$ from female donor kidneys $(212.5 \pm 38.1 \mathrm{~g})$. We do not have a good explanation for the discrepancy between the previous reports and ours. However, normal values of kidney weight could change under the influence of genetic factors and environmental factors such as dietary habits, daily water intake, etc. In our study population, all recipients and donors are Korean, and none of foreign recipient or foreign donor has been included. Given the fact that the nationality of Korean has been based on the principle of personal privilege for jurisdiction rather than the territorial principle (like in the USA), the participants in this study should be presumed to be ethnically uniform. In the ethnically uniform population of this study, the gender-related difference in kidney weight could be different from that of the previous reports.

The present data demonstrated that like the gender-related differences in the pre-operative Scr and Ucr of donors were directly associated with the differences in the parameters of metabolic demands of donors rather than with the weight of the donated kidney, the gender-related differences in post-transplant Scr and Ucr of recipients were directly associated with the differences in the parameters of metabolic demands of recipients rather than with the weight of transplanted kidney (renal mass supply) or with pre-donation renal functions of donors (functional supply). Therefore, these findings provide evidence that the gender-related differences in kidney graft functions such as Scr and Ucr after transplantation depend largely on the functional demands of recipient rather than on renal mass supply from donor. Of note, other measures of renal function such as erythropoetin synthesis, electrolyte or acid base balance and calcium metabolism were not evaluated in this study.

Based on the present study, the effect of gender on early graft function after living donor kidney transplantation may depend more on the 'recipient' rather than on the 'donor.' Renal graft function early after transplantation from a female donor was not inferior to that from a male donor, as a few reports suggested $(3,37)$. Even the graft weight from the female donors was not statistically lower than that from the male donors. On the contrary, recipient gender plays a role in the graft function after 
transplantation, and Scr and Ucr were significantly higher in male recipients despite there being no difference in the renal mass supply (kidney graft weight) or functional supply (pre-operative renal functions of donors) by the recipient gender. Moreover, we analysed the long-term outcome of the kidney graft to see any difference by the gender groups of donors and recipients. Given the fact that the study population was restricted to 195 living donor kidney transplant recipients that had neither ischemic injury, episode of rejection, nor any complication in the early post-operative period, the grafts had failed in only six cases during the follow-up period more than 18 months (three patients died with functioning graft at 2, 38, and 40 months post-transplantation, three grafts failed at 21, 39, and 43 months post-transplantation). We could not find any statistically significant difference in the graft survival until $3 \mathrm{yr}$ post-transplantation by the gender groups of donors and recipients. Three hundred and ninety-seven kidney transplants were performed during the study period. With overall 397 cases, we also analysed the survival of the kidney graft to see any difference by the gender groups of donors and recipients. We could not find any statistically significant difference in the graft survival until $3 \mathrm{yr}$ post-transplantation by the gender groups of donors and recipients.

Creatinine is a metabolic product of creatine and phosphocreatine, which are almost exclusively in muscle. Thus, creatinine is constantly produced from muscle, and its production is proportional to muscle mass, which also associated with the parameters of metabolic demands such as body weight, BSA and LBW. The fat component of the recipient's body has less of an effect on the parameters of graft function such as Scr, the amount of urinary Ucr and the amount of urinary protein excretion. However, the parameters of metabolic demands such as body weight, body surface area, LBW and BMI may overestimate metabolic demand in obese patients. Because Korean recipients and donors in this study were relatively lean (BMI of recipients $20.4 \pm 2.7 \mathrm{~kg} / \mathrm{m}^{2}$, BMI of donors $23.0 \pm 2.8$ $\mathrm{kg} / \mathrm{m}^{2}$ ), it is uncertain whether these findings could apply for more obese recipients and donors. Moreover, given the fact that the population of this study included adult donors and adult recipients (age of recipients $37.2 \pm 10.2 \mathrm{yr}$, age of donors $38.7 \pm$ $10.3)$, it is still uncertain whether these findings could apply for pediatric recipients. Further studies will be needed in an obese population or in a pediatric population to see if the gender-related differences of metabolic demands and renal mass supply in this study are effective in obese recipients or in younger recipients.
In conclusion, the 'recipient' gender may be more important than the 'donor' gender for early graft function after adult living donor kidney transplantation. The effect of recipient gender on early graft function depends on the metabolic demands which, on average, are higher in male recipients.

\section{Acknowledgements}

This work was supported by a 2004 grant from the Department of Medical Sciences, The Graduate School, Ajou University.

\section{References}

1. Vereerstraeten P, Wissing M, De Pauw L, Abramowicz D, Kinnaert P. Male recipients of kidneys from female donors are at increased risk of graft loss from both rejection and technical failure. Clin Transplant 1999: 13: 181.

2. Zeier M, Dohler B, Opelz G, Ritz E. The effect of donor gender on graft survival. J Am Soc Nephrol 2002: 13: 2570.

3. Meier-Kriesche HU, Ojo AO, Leavey SF et al. Gender differences in the risk for chronic renal allograft failure. Transplantation 2001: 71: 429.

4. Matas AJ, Gillingham KJ, Humar A, Dunn DL, SuthERLAND DE, NAJARIAN JS. Immunologic and nonimmunologic factors: different risks for cadaver and living donor transplantation. Transplantation 2000: 69: 54.

5. Kasiske BL, Umen JA. The influence of age, sex, race and body habitus on kidney weight in humans. Arch Pathol Lab Med 1986: 110: 55.

6. Brenner BM, Meyer TW, Hostetter TH. Dietary protein intake and the progressive nature of kidney disease: the role of hemodynamically mediated glomerular injury in the pathogenesis of progressive glomerular sclerosis in aging, renal ablation, and intrinsic renal disease. $\mathrm{N}$ Engl $\mathbf{J}$ Med 1982: 307: 652 .

7. Terasaki PI, Koyama H, Cecka JM, Guertson DW. The hyperfiltration hypothesis in human renal transplantation. Transplantation 1994: 57: 1450.

8. Kim YS, Moon JI, Kim DK, Kim SI, PARK K. Ratio of donor kidney weight to recipient body weight as an index of graft function. Lancet 2001: 357: 1180.

9. Z HOU YC, CECKA JM. Effect of sex on kidney transplants. Clin Transplant 1989: 1: 361.

10. Iguro T, Okazaki H, Sato T, Jimbo M, Oguma S. The effect of donor age and sex on cyclosporine associated nephrotoxicity. Transplant Proc 1989: 21: 1554.

11. Silbiger SR, Neugarten J. The impact of gender on the progression of chronic renal disease. Am J Kidney Dis 1995: 25: 515 .

12. Grossman C. Possible underlying mechanisms of sexual dimorphism in the immune response, fact and hypothesis. J Steroid Biochem 1989: 34: 241.

13. Enosawa S, Hirasawa K. Sex-associated differences in the survival of skin grafts in rats. Transplantation 1989: 47: 933.

14. Hirasawa K, Enosawa S. Effects of sex steroid hormones on sex-associated differences in the survival time of allogeneic skin grafts in rats: evidence that testosterone enhances and estradiol reverses the immunosuppressive activity of cyclosporine. Transplantation 1990: 50: 637.

15. DuBois D, DuBois EF. A formula to estimate the approximate surface area if height and weight be known. Arch Int Med 1916: 17: 863 . 


\section{Oh et al.}

16. Nicholson ML, Windmill DC, Horsburgh T, Harris KP. Influence of allograft size to recipient body-weight ratio on the long-term outcome of renal transplantation. Br J Surg 2000: 87: 314.

17. Miles AMV, Sumrani N, John S et al. The effect of kidney size on cadaveric renal allograft outcome. Transplantation 1996: 61: 894.

18. Kim SI, Kim YS, Kim MS, Moon JI, PARK K. True living donor kidney weight-to-recipient body weight ratio influences posttransplant 1-year renal allograft function. Transplant Proc 1998: 30: 3120.

19. KIM YS, KIM MS, HAN DS et al. Evidence that the ratio of donor kidney weight to recipient body weight, donor age, and episodes of acute rejection correlate independently with live-donor graft function. Transplantation 2002: 74: 280 .

20. MoOn IS, KIm YG, PARK JH et al. Influence of donor kidney size on immediate renal function (1 month) in kidney transplantation. Transplant Proc 1998: 30: 3666.

21. Pourmand G, Taheri M, Mehrsai AR, Nourijelyani K. Impact of donor nephron mass on outcomes in renal transplantation. Transplant Proc 2001: 33: 2828.

22. Pirsch JD, Armbrust MJ, Knechtle SJ et al. Obesity as a risk factor following renal transplantation. Transplantation 1995: 59: 631.

23. Meier-Kriesche HU, Vaghela M, Thambuganipalle R, Friedman G, Jacobs M, KaPLAN B. The effect of body mass index on long-term renal allograft survival. Transplantation 1999: 68: 1294.

24. Eschwege P, Trifa M, Randrianjohany A et al. Effects of donor and recipient weight differences on serum creatinine levels in renal transplantation. Transplant Proc 1995: 27: 2456.

25. Gaston RS, Hudson SL, Julian BA et al. Impact of donor recipient size matching on outcomes in renal transplantation. Transplantation 1996: 61: 383
26. Dinkel E, Ertel M, Dittrich M, Peters H, Berres M, Schulte-Wissermann H. Kidney size in childhood: sonographic growth charts for kidney length and volume. Pediatr Radiol 1983: 15: 38.

27. HAN BK, BABCOCK DS. Sonographic measurements and appearance of normal kidneys in children. Am J Roentgenol 1985: 145: 611

28. KARN MN. Radiographic measurements of kidney section area. Ann Hum Genet 1962: 25: 379.

29. Emamian SA, Nielsen MB, Pedersen JF, Ytte L. Kidney dimensions at sonography: correlation with age, sex, and habitus in 665 adult volunteers. Am J Roentgenol 1993: 160: 83.

30. Rasmussen SN, Haase L, Kueldsen H, Hancke S. Determination of renal volume by ultrasound scanning. J Clin Ultrasound 1978: 6: 160.

31. Bunke M, Marx MA, Abul-Ezz S, Almouist G, Barone G, KETEL B. The poor accuracy of indirect measurements of cadaveric donor kidney weights. Clin Transplant 1999: 13: 253.

32. Neugarten J, Kasiske B, Silbiger SR, Nyengaard JR Effects of sex on renal structure. Nephron 2002: 90: 139

33. de la Grandmaison GL, Clairand I, Durigon M. Organ weight in 684 adult autopsies: new tables for a Caucasoid population. Forensic Sci Int 2001: 119: 149.

34. WALD H. The weight of normal adult human kidneys and its variability. Arch Pathol 1937: 23: 493.

35. Boyd E. Normal variability in weight of the adult human liver and spleen. Arch Pathol 1933: 16: 350.

36. Paivansalo MJ, Merikanto J, Savolainen MJ et al. Effect of hypertension, diabetes and other cardiovascular risk factors on kidney size in middle-aged adults. Clin Nephrol 1998: 50: 161.

37. Valdes F, Pita S, Alonso A et al. The effect of donor gender on renal allograft survival and influence of donor age on posttransplant graft outcome and patient survival. Transplant Proc 1997: 29: 3371 . 